\title{
Dispersion Hardened Gold
}

\section{A NEW MATERIAL OF IMPROVED STRENGTH AT HIGH TEMPERATURES}

\author{
M. Poniatowski and M. Clasing \\ Metal Research Laboratories, Degussa, Wolfgang, Federal Republic of Germany
}

A limitation to the usefulness of gold in the industrial field is its low hardness and strength, particularly at elevated temperatures. This paper describes the production of a hardened gold by the simultaneous precipitation of gold and of titanium hydroxide, followed by annealing and extrusion. This material possesses excellent cold working properties and considerably higher hardness, tensile strength and creep strength than pure gold at higher temperatures.

The remarkable corrosion resistance of gold, coupled with its excellent conductivity, has created a wide field of application for this metal in modern industrial practice. The only drawback from the technical point of view is its poor Brinell hardness value, which drops from about 13 at room temperature to less than 5 above $700^{\circ} \mathrm{C}$. Alloying, although producing improved mechanical strength, will lower its electrical conductivity to a marked degree; its corrosion resistance is also affected if gold is alloyed with base metals. This situation had prompted the desire to build greater high temperature hardness and strength into the metal while retaining the specific properties of gold. On the basis of modern technology in the field of hardening processes, dispersion hardening offers a suitable and practicable solution. The method arrests dislocation migration under mechanical stress while building up thermally stable dislocation systems by the addition of extremely small extraneous particles, usually of an oxidic nature, of great thermodynamic stability.

There is at present no well defined hardening theory for a polycrystalline matrix, but tests on single crystals $(1,2,3,4)$ have shown that the diameter and distance apart of the dispersed particles combined with their distribution in the matrix are the decisive factors for the degree of hardness that can be obtained. As a rule, the particle size should, where possible, be less than 1 micron in diameter and the distance between particles not more than five or ten times the diameter.

As far as particle size and homogeneous distribution are concerned, the incorporation of dispersed particles can best be achieved by the internal oxidation of an alloy in which the addition possesses high enthalpy towards a stable oxide. This method is subject to an adequate oxygen diffusion in the matrix. In practice, dispersion hardening of noble metals by internal oxidation has been successfully carried out on silver and platinum $(5,6)$. However, internal oxidation of gold alloys is impracticable due to insufficient solubility of the oxygen in the matrix and the consequent very small diffusion effect. Since production of dispersion hardened materials by powder metallurgical methods involving mixtures of metallic and oxide particles generally leads to inhomogeneous distribution of the dispersed elements, this type of process is doomed to failure. Simultaneous precipitation of the matrix and the disperse system as a compound in an aqueous solution, with subsequent or simultaneous reduction of the parent metal, appears to be more promising. N. Fuschillo and M. L. Gimpl $(7,8)$ have carried out relevant tests on gold to which $\mathrm{ThO}_{2}$ and $\mathrm{Al}_{2} \mathrm{O}_{3}$ were added.

The use of titanium as a dispersant seemed to us to hold out even greater promise of success, since its hydroxide dehydrolises at low temperatures. According to Gmelin the anatase produces the stable high temperature modification rutile during annealing between 830 and $950^{\circ} \mathrm{C}$.

For the purpose of producing the mixed powder a strongly acid gold chloride solution is mixed with a titanium tetrachloride solution and added drop by drop to an ammoniacal hydrazine solution constantly stirred. Elemental gold is precipitated as a powder together with a conglomerate consisting of $\mathrm{Ti}(\mathrm{OH})_{4}$, $\mathrm{Ti}(\mathrm{OH})_{2}$ and $\mathrm{TiO}_{2}$. The product settles easily and is separated by decanting and filtering. Decomposition of the hydroxides is effected by heating for several hours in a vacuum of $10^{-2}$ torr at up to $700^{\circ} \mathrm{C}$. 
The powder is compacted into billets $55 \mathrm{~mm}$ diameter. After heating to $850^{\circ} \mathrm{C}$ these are extruded with an extrusion ratio of about 21:1 into rods $12 \mathrm{~mm}$ diameter. After repeated 80 per cent area reductions followed by interannealing (1 hour at $700^{\circ} \mathrm{C}$ in air) it became possible without difficulty to draw wires down to approximately 100 micron diameter for ductility tests.

Such dispersion hardened gold contains 0.42 per cent by weight (1.85 per cent by volume) of $\mathrm{TiO}_{2}$ with a rutile structure. The average oxide particle size is approximately 0.5 micron. The photomicrograph shows the distribution of the dispersoids, formed into lines as a consequence of extrusion and drawing. Even after long periods of heating (up to 200 hours) at $900^{\circ} \mathrm{C}$ no evidence of oxide agglomeration was found by microscopic examination.

The Brinell hardness of the extruded product was 55 , increasing after 80 per cent area reduction in rolling to about 80 , and falling after annealing for one hour at $500^{\circ} \mathrm{C}$ to the original value.

Figure 1 shows thermal softening as a function of the annealing temperature. The corresponding values for gold are given for comparison. The hardness of the dispersion hardened gold in the annealed con-
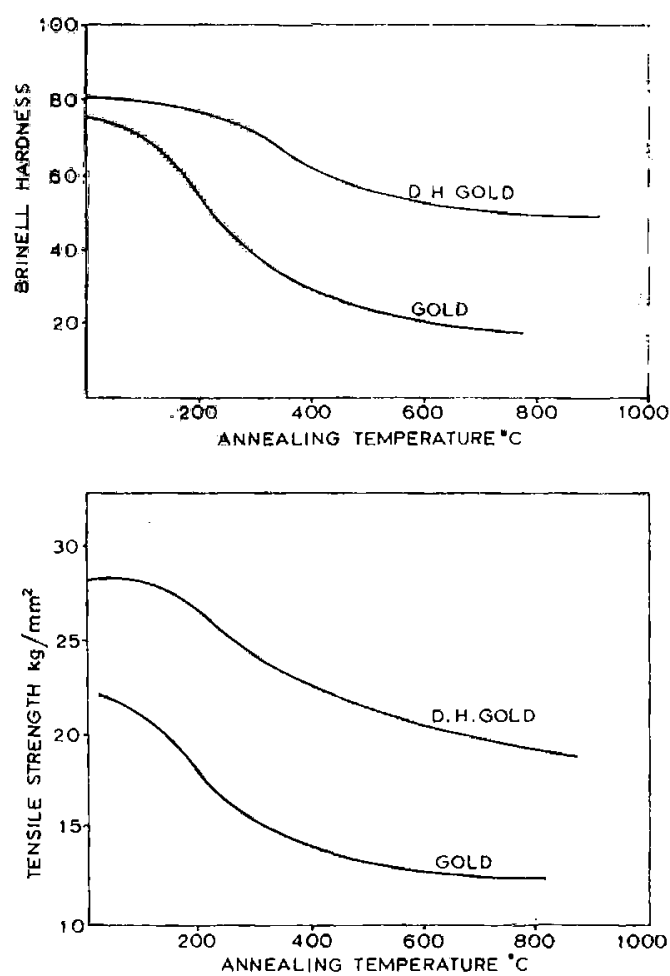

Fig. 1 The effects of annealing on the Brinell hardness and tensile strength of dispersion hardened gold by comparison with pure gold. Determined on specimens of $2 \mathrm{~mm}$ diameter wire drawn by $80 \%$ reduction of area and heated for 1 hour.

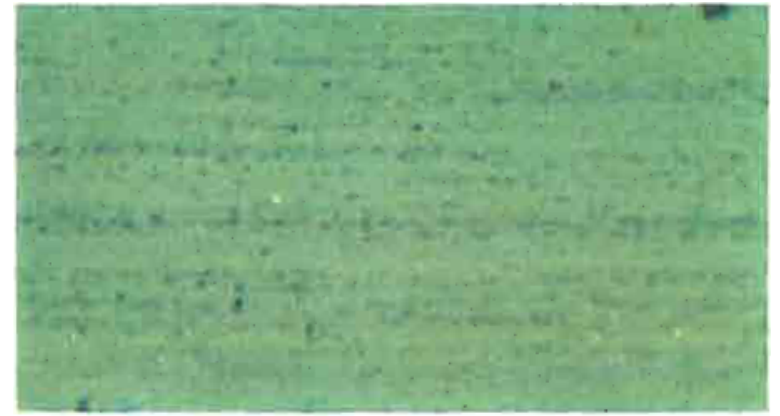

Structure of a longitudinal section of extruded and drawn wire. Although formed into stringer-like bands by working, the dispersed particles are seen to be well distributed and comparable in diameter with the limit of resolution of the microscope $\times 1000$

dition is approximately three times, and the tensile strength approximately one and a half times, that of pure gold.

The high temperature tensile properties of the dispersion hardened gold and of pure gold are plotted in Fig. 2. The slight scatter of the values found (approximately \pm 10 per cent) can be represented without undue distortion by two straight lines. The superiority of dispersion hardened gold becomes increasingly apparent the higher the testing temperature. At room temperature the ratio

\section{$\frac{\text { Tensile strength } \mathrm{Au}-\mathrm{TiO}_{2}}{\text { Tensile strength } \mathrm{Au}}$}

is approximately 1.45 , rising to 1.65 at $400^{\circ} \mathrm{C}$ and to 2.5 at $800^{\circ} \mathrm{C}$.

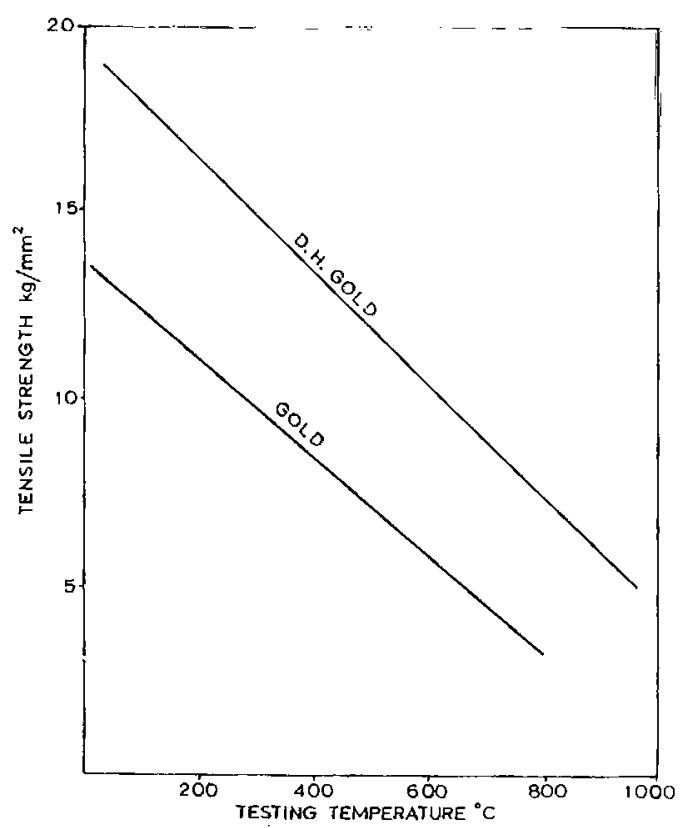

Fig. 2 The high temperature tensile strength of dispersion hardened gold by comparison with pure gold. Determined on specimens of $2 \mathrm{~mm}$ diameter wire, annealed for 1 hour at $600^{\circ} \mathrm{C}$ 
Creep Strength of Dispersion Mardened Gold

\begin{tabular}{c|c} 
Temperature & $\begin{array}{c}\text { Stress in } \mathrm{kg} / \mathrm{mm}^{2} \\
\text { for } 100 \text { hour life }\end{array}$ \\
400 & 9.8 \\
500 & 7.0 \\
600 & 6.2 \\
700 & 4.0 \\
800 & 2.8 \\
900 & 1.3 \\
\hline
\end{tabular}

Creep Strength of Pure Gold

395

500

2.60

1.56

When a material is subject to continuous thermal and mechanical stresses at a constant rate, creep occurs which sooner or later leads to fracture. The creep resistance of dispersion hardened gold wires $2 \mathrm{~mm}$ in diameter was determined as an important technical parameter during stress periods of up to 100 hours. These 100 hour values have been compiled over a temperature range from $400^{\circ}$ to $900^{\circ} \mathrm{C}$ and are shown in the table. The equivalent values for gold (9) are included for comparison. The 100 hour creep resistance of dispersion hardened gold at $400^{\circ} \mathrm{C}$ is roughly four times, and at $500^{\circ} \mathrm{C}$ approximately five times, that of gold, and represents a

substantial improvement over dispersion hardening carried out with $\mathrm{Al}_{2} \mathrm{O}_{3}$ or $\mathrm{ThO}_{2}$ (7 and 8).

The specific resistance of dispersion hardened gold is slightly higher-some 10 per cent-than that of pure gold. Determinations on $0.5 \mathrm{~mm}$ diameter wire at $20^{\circ} \mathrm{C}$ gave a figure of $2.44 \mu \mathrm{ohm}-\mathrm{cm}$ for hard drawn wire, and $2.40 \mu \mathrm{ohm}-\mathrm{cm}$ after annealing in air at $800^{\circ} \mathrm{C}$ for 10 hours. These values compare with $2.125 \mu \mathrm{ohm}-\mathrm{cm}$ for pure gold.

Dispersion hardened gold is capable of being brazed. Wires of $1.5 \mathrm{~mm}$ diameter were butt brazed, and tensile tests showed that the strength of the joints was greater than that of the wires in all cases.

Titanium oxide dispersion hardened gold is the subject of a Degussa Patent Application, BRD P2052749 of October $28 \mathrm{th}, 1970$.

\section{References}

1 E. Orowan, Symp. Internal Stresses in Metals and Alloys, Inst. Metals, 1948, 451

2 F. R. N. Nabarro, Proc. Phys. Soc, 1946, 58, 669

3 F. R. N. Nabarro, Adv. Phys., 1952, 1, 269

4 M. F. Ashby, Ph.D. Thesis, Cambridge Univ, 1961 . M. F. Ashby, Phil. Mag., 1966, 14, 1157; R, Ebeling and M. F. Ashby, Phil. Mag., 1966, 13, 805

5 M. Poniatowski and M. Clasing, Z. Metallkunde, 1968 , 59,165

6 Degussa, Patentanmeldung BRD, P 2002886, January 23rd, 1970.

7 N. Fuschillo and M. L. Gimpl, F. Mater. Sci., 1970, 5, 1078

8 M. L. Gimpl and N. Fuschillo, F. Metals, 1971, 23, 39

9 Edelmetall-Taschenbuch, Degussa, 1967

\section{Structure of Vacuum Evaporated Gold Films}

\section{SINGLE CRYSTALS PRODUCED BY HEAT TREATMENT}

The vacuum deposition of thin gold films is a widely used process and a considerable amount of research has been devoted to the study of the structure of such films. Special interest has centred on the phenomenon of epitaxy in which a film deposited on a single crystal substrate also exhibits single crystal form in a definite orientation relative to the substrate. It has been shown that for given deposition conditions a certain minimum substrate temperature is required to obtain epitaxial films, although no agreement has been reached on what this temperature is.

The recent work on the vacuum eyaporation of gold on to cleaved rock salt by G. B. Priebsch and W. Fischer at the VEB Keramische Werke at Hermsdorf in East Germany (Hermsdorfer Tech. Mitt., 1971, 32, (11), 1022), has shown that single crystal films can be obtained by the heat treatment of a polycrystalline deposit at $450^{\circ} \mathrm{C}$ in air. The change from a polycrystalline deposit to an orientated deposit was shown by electron diffraction patterns, the Debye-Scherrer rings produced by randomly orientated polycrystalline materials giving place to the spot diffraction pattern obtained from single crystals or a number of crystals in the same orientation. The values of the d-spacings

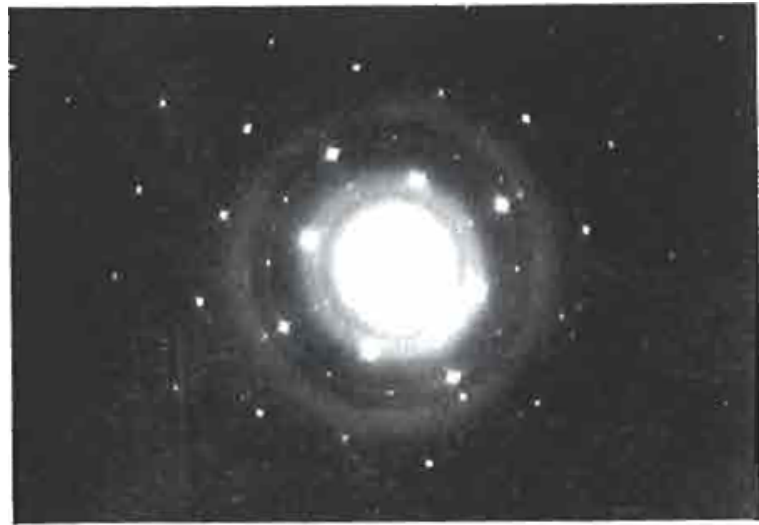

Spot diffraction pattern from orientated crystals after heat treatment of the initial film for 1 hour at $450^{\circ} \mathrm{C}$ in air

for these films are in excellent agreement with those found by Pashley (Phys. Status Solidi, 1965, 10, 153), in his work on the deposition of epitaxial gold films on rock salt.

C. $\mathrm{H}$. 